FACULDADE DE CIÊ NCIAS ECONÔ MICAS DA UFRGS

REESTRUTURAÇÁ O DA PRODUÇÁ O AGRICOLA NO RIO GRANDE DO SUL, DE 1970 A 1996 E UMA ESTIMAÇȦ O PARA 2012 TIAGO WICKSTROM ALVES

A CRIMINALIDADE NA RECIAO METROPOLTANA DE SALVADOR JOSÉ CARRERA FERNANDEZ, LUIZ FERNANDO LOBO

COMPEIITIVIDADE INTERNACIONAL EM SOFTWARE: UM ESTUDO SOBRE A EXPERIÊNCIA DE FLORIANÓ POLIS HOVÉDO NUNES LINS

MODELOS DE ORGANIZAÇẢ O E REPARTIÇẢ O DE RENDAS NA CADEIA PRODUTIVA DO GÁS NATURAL.

HELder QUEIROZ PINTO Jú NIOR, RODOLFO TORRES dOS SANTOS

REGIMES MONETÁ RIOS E DIVIDA PÚ BLICA: UMA ANÁ LISE DE MECANISMOS ALTERNATIVOS DE COORDENAÇÃO MACROECONÓ MICA

manoel Carlos de Castro Pires

ECONOMIA DOS RECURSOS NATURAIS E SEUS INDICADORES DE ESCASSEZ: UMA QUESTÃ O DE SUSTENTABILIDADE ANDREA SALES SOARES DE AZEVEDO MELO

O ECOPROTECIONISMO AGRICOLA NA UNIĀ O EUROPEIA E SEUS POSSIVEIS IMPACTOS SOBRE A ECONOMIA BRASILEIRA Rodrigo daniel Feix, Clá udio R. Fóffano Vasconcelos

PADRÓ ES DE DESENVOLVIMENTO, FUNÇ Ó ES ESTATAIS E ENDIVIDAMENTO NO CAPITALISMO CONTEMPORÁNEO paulo Balanco, Eduardo Costa Pinto

A INTERNACIONALIZAÇÃO DO VAREJO A PARTIR DOS CASOS WAL-MART E CARREFOUR

Armando joảo dalla Costa

UMA ANÁ LISE ECONOMÉTRICA DO FUTEBOL BRASILEIRO ARI Francisco de Araujo JR, Clá udio D. SHIKIDA, LEONARDO M. MONASTERIO

O BRASIL E A ECONOMIA INTERNACIONAL: RECUPERAÇÃ O E DEFESA DA AUTONOMIA NACIONAL

RESENHA DE ALEXANDRE CÉ SAR CUNHA LEITE

REGIMES MONETÁ RIOS: TEORIA E A EXPERIÊNCIA DO REAL ResenHa de Fernando Ferrari Filho

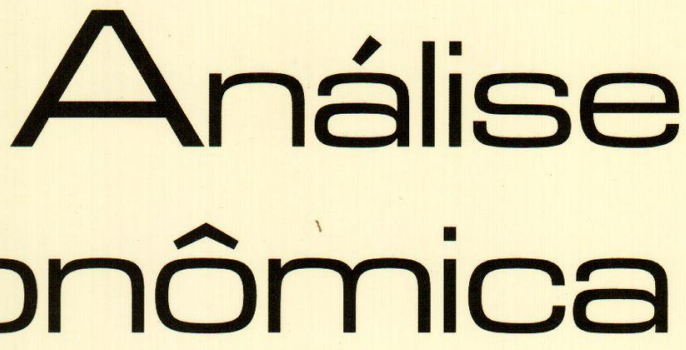


Universidade Federai. do Rio Grande do Sul Reitor: Prof José Carlos Ferraz Hemnemann

Facul dade de Cuéncias Economicas

Diretor: Prof. Gentil Corazza

Ceniro de Estudos f Prequisas Economicas

Diretor: Prof. Lovois de Andrade Miguel

Depariamenio de Crências Economicas

Chefe: Prof Ricardo Dathein

Departamento de Cîncias Coniábeis f A tuaria Chefe: Prof. Ceno Odilo Kops

Curso de Pós-Graduaçó em Economia

Coordenador: Prof. Fernando Ferrari Filho

Curso de Pos-Grainaça em Desenvolvimento RuRAI

Coordenador: Prof. Paulo Dabdab Waquil

Conseluo Eni tokial: André Moreira Cunha (UFRGS) Carlos G. A. Mielitz Netto (UFRGS), Carlos Henrique Hom (UFRGS). Eduardo A. Maldonado Filho (UFRGS). Eleutério F S. Prado (USP), Eugênio Lagemann (UFRGS), Fernando Cardim de Carvalho (UFRJ). Femando Ferrari Filho (UFRGS), Fernando de Holanda Barbosa (FGV/RJ), Flávio Augusto Ziegelmann (UFRGS), Flávio Vasconcellos Comin (UFRGS), Gentil Corazza (UFRGS), Giácomo Balbinot to Neto (UFRGS), Gustavo Franco (PUC/RJ) Hélio Henkin (UFRGS), Jan A. Kregel (UNCTAD), João Rogério Sanson (UFSC), Joaquim Pinto de Andrade (UnB), Júlio César Oliveira (UFRGS), Luiz Estrella Faria (UFRGS), Luiz Paulo Ferreira Nogueról (UFRGS), Marcelo S Portugal (UFRGS), Maria Alice Lahorgue (UFRGS), Octávio Augusto Camargo Conceicão (UFRGS), Paul Davidson (University of Tennessee), Paulo D. Waquil (UFRGS), Pedro C. D. Fonseca (UFRGS), Philip Arestis (University of Cambridge), Ricardo Dathein (UFRGS) Ronald Otto Hillbrecht (UFRGS), Sabino da Silva Porto Jr (UFRGS), Sérgio M. M. Monteiro (UFRGS), Stefano Florissi (UFRGS) e Werner Baer (University of IIIinois at Urbana - Champaign)

Comissão Emroniai: Eduardo Augusto Maldonado Filho, Fernando Ferrari Filho, Hélio Henkin. Marcelo Savino Portugal, Paulo Dabdab Waquil e Sérgio Marley Modesto Monteiro.

EnIrok: Sérgio Marley Modesto Monteiro

Ediror Adjun ro: Hélio Henkin

Secretário: Emerson Douglas Neves

REVISÃo DE IEX ros: Vanete Ricacheski

Emioração: Núcleo de Editoração e Criação da

Gráfica da UFRGS - Janaína Horn e Junia Saedt

Fundador: Prof Antonio Carlos Santos Rosa
Os materiais publicados na revista Análise Econômica são da exclusiva responsabilidade dos autores. É permitida a reprodução total ou parcial dos trabalhos, desde que seja citada a fonte. Aceita-se permuta com revistas congêneres. Aceitam-se, também, livros para divulgacão, elaboraça de resenhas e recensões Toda correspondência: material para publicação (vide normas na terceira capa), assinaturas e permutas devem ser dirigidos ao seguinte destinatário:

Prof. Sérgio Marley Modesto Monteiro Revista Andilse Económica - Av. João Pessoa, 52 CEP 90040-000 PORTO ALEGRE - RS, BRASIL Telefones: (051) $33163513 / 33164164$

Fax: (051) 33163990 - E-mail: rae@vortex ufrgs.br

A Revista Análise Econômica agradece a colaboração dos pareceristas do número 43, abaixo relacionados:

Adalmir Antonio Marquetti

André Moreira Cunha

Carlos José Caetano Bacha

Carlos Mielitz. Netto

Clailton Ataídes de Freitas

Claudio Roberto Fóffano Vasconcelos

Eduardo Ernesto Filippi

Eduardo Pontual Ribeiro

Eleuterio Fernando da Silva Prado

Fernando J Cardim de Carvalho

Fernando Augusto Mansor de Mattos

Fernando Ferrari Filho

Flávio Tosi Feijó

Flavio Vilela Vieira

Francisco Paulo Cipolla

Gentil Corazza

Gíacomo Balbinotto Neto

Helio Henkin

Jefferson Andronio Ramundo Staduto

João de Deus Sicsú Siqueira

José Carrera Fernandes

Leonardo Monteiro Monasterio

Luís Fernando de Paula

Luis Roberto Nascimento

Manoel Carlos de Castro Pires

Octavio Augusto Camargo Conceição

Patrízia Raggi Abdallah

Robson Antonio Grassi

Ronald Otto Hilbrech

Tiago Wickstrom Alves

Tito Belchior Silva Moreira

Análise Econônica

Ano 23, n ${ }^{\circ} 44$, setembro, 2005 - Porto Alegre

Faculdade de Ciências Economicas, UFRGS, 2000

Periodicidade semestral, março e setembro

1. Teoria Econômica - Desenvolvimento Regional -

Economia Agrícola - Pesquisa Teórica e Aplicada -

Periódicos. I.. Brasil

Faculdade de Ciências Econômicas,

Universidade Federal do Rio Grande do SuI

CDD 330.05

CDU $33(81)(05)$ 


\title{
Regimes Monetários: teoria e a experiência do real
}

\author{
André de Melo Modenesi
}

Fernando Ferrari Filho*

\section{Resenha}

Ao longo dos últimos anos, mais especificamente desde o Plano Real, a política monetária não tem sido operacionalizada de forma contra-cíclica: por um lado, entre julho de 1994 e janeiro de 1999, período no qual a taxa de câmbio era relativamente estável, a taxa de juros foi manipulada de forma a equilibrar, através do ingresso de capitais de portfolio, o balanço de pagamentos; por outro, a partir de junho de 1999, quando o Banco Central do Brasil (BCB) implementou o regime de metas de inflação, a essência da política monetária tem sido explicitamente recessiva conforme sua expectativa de inflação. Nunca é demais ressaltar que o regime de metas de inflação é um desdobramento do regime tradicional de metas monetárias e, portanto, se apóia no princípio da neutralidade monetária. Centrando as atenções especificamente no período pós-regime de metas de inflação, as principais críticas à adoção do referido regime para a economia brasileira estão relacionadas ao fato de que (i) o BCB parece não perceber que, no real world, os fatores reais e monetários da economia não estão dissociados e (ii) as metas de inflação, em seis anos de vigência do regime de metas de inflação, não foram cumpridas em três anos seguidos (2001, 2002 e 2003), o que resulta em perda de credibilidade desse regime.

Pois bem, no momento em que se retoma o debate teórico acerca do papel e dos efeitos transmissores da política monetária no cotidiano da economia brasileira, cabe saudar o livro de André de Melo Modenesi, intitulado Regimes Monetários: Teoria e a Experiência do Real (São Paulo, Editora Manole, 2005, 438p.). Nesse livro, o autor apresenta, de forma didática e com muita competência, a lógica operacional dos principais regimes monetários - metas monetárias, metas cambiais e metas de inflação - e mostra como os referidos regimes têm sido implementados e dinamizados na economia brasi-

* Professor Titular da Universidade Federal do Rio Grande do Sul e Pesquisador do CNPq. Email: ferrari@ufrgs.br. 
leira a partir do Plano Real. Nesse particular, a principal contribuição do autor consiste em explicitar que a discussão acadêmica sobre os regimes monetários e a política monetária, apesar de "novas roupagens", ainda está centrada em duas concepçōes teóricas, quais sejam, keynesiana e monetarista.

O Livro está dividido em seis capítulos. Nos três primeiros, o autor analisa os fundamentos teóricos e as implicações dos regimes de metas monetárias, de metas cambiais e de metas de inflação. Nos capítulos quatro, cinco e seis, a estabilização monetária, a partir do Plano Real, é analisada à luz dos referidos regimes.

No primeiro capítulo, as atenções são voltadas para a operacionalização dos regimes cambiais. Assim sendo, André Modenesi descreve as vantagens e desvantagens dos principais regimes cambiais, quais sejam: padrão-ouro, Bretton Woods e currency board. Em termos conclusivos, o capítulo sinaliza que, por um lado, o regime de câmbio relativamente rígido apresenta uma vantagem específica que consiste na subordinação da inflação doméstica à inflação externa; em contrapartida, esse regime apresenta duas cruciais desvantagens: a política monetária perde autonomia e o banco central deixa de exercer sua função de emprestador de última instância. Por outro, as vantagens e desvantagens dos regimes de câmbio relativamente flexíveis são que o balanço de pagamentos. tende para uma posição de equilíbrio e, portanto, as autoridades monetárias não precisam dispor de reservas cambiais robustas e choques externos tendem, via alterações na taxa de câmbio, a ser propagados para os preços domésticos, respectivamente.

Os capítulos dois e três discutem os regimes de metas monetárias e metas de inflação, tendo como referência as concepções teóricas monetarista e novo-clássica.

No segundo capítulo, o autor, partindo de uma Curva de Philips ampliada pelas expectativas (versão aceleracionista da Curva de Phillips à la FRIEDMAN-PHELPS), analisa o papel e os efeitos transmissores da política monetária, enfatizando as opçōes de regras e de discrição desta última. Cabe sublinhar que os apêndices desse capítulo, quais sejam, "A revolução keynesiana, a síntese neoclássica e a contra-revolução monetarista", "A história da Curva de Phillips" e "Verticalismo versus horizontalismo", apresentam uma interessante e breve compreensão da evolução da teoria macroeconômica, um histórico da existência do trade-off entre inflação e desemprego e uma síntese do debate estabelecido entre os economistas que consi- 
deram a oferta monetária perfeitamente elástica e aqueles que acreditam que ela é perfeitamente inelástica.

O capítulo três, por sua vez, centra as atenções nos modelos novoclássicos, cuja essência consiste em formular microfundamentos para a análise macroeconômica, quais sejam, os princípios de otimização e as expectativas racionais. Ao longo do capítulo, o autor apresenta os fundamentos teóricos do regime de metas de inflação, bem como formula e discute as implicações dos modelos de independência do banco central. Em relação à independência do banco central, é apresentada uma discussão contemporânea e pertinente, qual seja: autonomia operacional vis-à-vis independência funcional da referida Instituição.

Nos capítulos subseqüentes, André Modenesi ilustra a aplicabilidade dos regimes monetários à luz da experiência do Plano Real. Inicialmente, é apresentada uma resenha sobre algumas das principais teorias inflacionárias e de suas proposiçōes de política antinflacionária, (neo)estruturalistas e inercialistas, desenvolvidas por renomados economistas latino-americanos, Celso Furtado, Ignácio Rangel e Mário H.Simonsen, entre outros. $\mathrm{O}$ objetivo dessa resenha é mostrar que os "antecedentes do Plano Real", tanto em termos de diagnóstico inflacionário, quanto no que diz respeito à adoção de políticas de controle do processo inflacionário, identificam-se com essas concepçōes teóricas. Em seguida, são apresentadas as etapas do plano de estabilização econômica implementado no Brasil em 1994: Plano Real. Nesse particular, a essência é mostrar que as âncoras cambial e monetária foram importantes para debelar o processo crônico de hiperinflação observado no País no início dos anos 1990: a âncora cambial objetivou estabilizar a dinâmica inflacionária, ao passo que a âncora monetária foi importante para restaurar o equilíbrio do balanço de pagamentos. Finalmente, o autor apresenta os motivos que levaram o Brasil a adotar o regime de metas de inflação em 1999, bem com analisa e critica a performance do referido regime.

Enfim, o livro de André Modenesi é uma contribuição interessante para aqueles que querem ir adiante na compreensão tanto da lógica dos regimes monetários quanto das discussões sobre alternativas de políticas de estabilização para países emergentes, dentre os quais o Brasil, em que, parafraseando John Maynard Keynes, a estabilidade macroeconômica não se restringe tão-somente ao controle da dinâmica inflacionária, mas, sim, à combinação de pleno emprego e preços estáveis. 